\title{
Chronotherapy in the treatment of epilepsy
}

\author{
This article was published in the following Dove Press journal: \\ ChronoPhysiology and Therapy \\ 26 November 2014 \\ Number of times this article has been viewed
}

\section{David A Stanley' \\ Sachin S Talathi ${ }^{2}$ \\ Paul R Carney ${ }^{3}$ \\ 'Department of Mathematics and Statistics, Boston University, Boston, MA, USA; ${ }^{2}$ Qualcomm Research Center, San Diego, CA, USA; ${ }^{3}$ Departments of Pediatrics, Neurology, Neuroscience, and Biomedical Engineering, University of Florida, Gainesville, FL, USA}

Correspondence: David A Stanley Department of Mathematics and Statistics, Boston University,

II I Cummington Street, Boston, MA 022I5, USA

Email stanleyd@bu.edu

Paul R Carney

Departments of Pediatrics, Neurology,

Neuroscience, and Biomedical

Engineering, University of Florida, 1600 SW, Archer Road, Gainesville, FL 32610, USA

Email carnepr@peds.ufl.edu
Abstract: The presence of natural 24-hour oscillations within the body provides often overlooked opportunities for treatment of epilepsy. By simply tailoring the drug regimen to an individual's circadian rhythm, recent studies suggest one can improve the effectiveness of antiepileptic drugs, while reducing side effects. Daily variations in seizure occurrence and drug side effects create optimal timing windows for delivery of medication. Conversely, in certain epilepsy syndromes, there is growing evidence that both sleep and circadian rhythm can be distorted or misaligned. Thus, therapeutic re-entrainment of rhythms via application of zeitgebers (chronobiotics) may represent an untapped opportunity for improving patient quality of life.

Keywords: circadian, epilepsy, sleep, chronotherapy, chronopharmacology, personalized medicine

\section{Epilepsy and management issues in treatment}

Circadian rhythms play a role in many disease states but are rarely considered in their management. This is certainly true in the epilepsies. The actual impact of the circadian rhythm on the development of epilepsy, the occurrence of individual seizures, and the response to intervention are poorly understood. Nevertheless, some circadian influences have long been recognized such as the risk for early morning myoclonus in juvenile myoclonic epilepsy.

For most patients, the first line of treatment of epilepsy is pharmacological therapy. The selection of a particular antiepileptic medication for a given subtype of epilepsy has long been the subject of controversy. Numerous factors may be considered when selecting an antiepileptic drug (AED), such as epilepsy syndrome, other medical disorders (headache, bone marrow dysfunction, and liver insufficiency), baseline cognitive dysfunction, neurological function, somatic and psychiatric comorbidities, demographic factors, cost, and medication side effects.

In terms of patient quality of life, drug side effects can have a substantial impact. Side effects related to antiepileptic medications are numerous and varied. Sedation and impairment of cognitive function range from minimal with some medications to profound with others, such as phenobarbital. Electrolyte imbalances can occur with carbamazepine and oxcarbazepine. Dizziness can occur with numerous seizure medications.

The reciprocal relationship between epilepsy and 24-hour rhythms has been well established for many epilepsy syndromes (reviewed in the "Diurnal rhythms and epilepsy" section, and elsewhere ${ }^{1-8}$ ). Endogenous 24-hour rhythms can influence epileptic seizures, creating 24-hour patterns of seizure recurrence. Conversely, 
a number of studies have shown that epilepsy and AEDs have a detrimental effect on sleep and circadian rhythms.

Until now, the effects of 24-hour rhythms on seizure management have been, in large part, ignored. As we shall discuss, therapy effectiveness might be improved and side effects minimized by tailoring the therapy to the peak seizure time of an individual. This chronotherapeutic approach may apply to the selection of pharmacological therapy, the timing of pharmacological therapy, and the programming of stimulator devices. Additionally, chronic sleep and circadian disruption can have negative consequences, including cognitive impairment, emotional disorders, and increased susceptibility to seizures. ${ }^{9-11}$ Direct treatment of these disruptions may help alleviate comorbid pathologies and perhaps the prevalence of seizures themselves.

Chronotherapeutic treatment of epilepsy, termed chronoepileptology ${ }^{8}$ presents opportunities for improving epilepsy therapy, reducing side effects, and elevating patient quality of life. In this review, we shall first provide an overview of the circadian system (see "Circadian oscillations in the brain" section). This will be followed by a discussion of the reciprocal interaction between epilepsy and 24-hour rhythms (see "Diurnal rhythms and epilepsy" section). We will then introduce common strategies in chronotherapy and chronopharmacology and discuss how these apply to epilepsy (see "Chronopharmacology and epilepsy" section). Finally, we shall review several previous clinical studies of chronotherapy in epilepsy (see "Current and emerging chronotherapeutic treatments" section) and discuss how chronotherapy might improve patient care (see "Implications for enhanced patient care" section).

\section{Circadian oscillations in the brain Hierarchy of oscillators}

This section provides a brief overview of the circadian system. Given the focus of this review on epilepsy, we concentrate specifically on neurological oscillations within the brain and their interaction with the wake-sleep cycle.

Diurnal rhythms are oscillations having near 24-hour period. We shall use the terms diurnal rhythms and 24-hour rhythms interchangeably. Circadian rhythms are biological diurnal oscillations that persist in the absence of external cues. They are ubiquitous in biological systems, ranging from bacteria to the human brain. In mammals, coordination of these rhythms is achieved by the circadian timing system, which is typically divided into three functional units, ie, an input, a pacemaker, and an output. ${ }^{8,12}$

In mammals, the primary circadian pacemaker is located in the suprachiasmatic nucleus (SCN). The near 24-hour oscillations of the SCN are influenced by both external stimuli (zeitgebers) and also internal inputs. A primary input to the SCN arises from the photoreceptors in the retina, which transmit information about the environmental light-dark cycle. These photoreceptors include both conventional rods and cones and also retinal ganglion cells, which serve as the non-image-forming photoreceptors for the brain. ${ }^{13}$ Secondary non-photic inputs to the $\mathrm{SCN}$ arise from the intergeniculate leaflet, from the raphe nuclei, and from several other sites in the brain that transmit information to the SCN about feeding and temperature patterns. ${ }^{12}$ Non-photic stimuli can induce increased arousal and therefore changes in behavior that can influence the phase and period of circadian rhythms in certain animals. ${ }^{14}$

While the SCN serves as the master clock of the circadian system, it does not exhibit a great many efferent projections. Rather, the circadian system relies on a number of intermediary nuclei that are organized into a hierarchicaltype network. ${ }^{15}$ This hierarchy includes both feedforward and feedback connections. Additionally, a number of recent studies have identified independent peripheral circadian oscillators that form part of the circadian network and that, like the SCN, maintain 24-hour oscillations in isolation. ${ }^{16,17}$ These nuclei receive the SCN clock signal, integrate it with other information, and then transmit it throughout the body, much in the same way the $\mathrm{SCN}$ integrates information from the retina. A standard example is the circuit that controls the release of melatonin. While melatonin is a principal output of the circadian system, it is produced by the pineal gland and its release is indirectly controlled by the SCN. Specifically, the SCN relies on a polysynaptic pathway via the paraventricular nucleus and the superior cervical ganglion to finally reach the pineal gland. ${ }^{18}$ Melatonin is then released into the bloodstream to exert effects throughout the body and also to exert a feedback effect on the SCN itself. ${ }^{19}$

\section{Circadian regulation of the wake-sleep cycle}

Sleep is regulated by the interaction of circadian and homeostatic processes. The circuit controlling sleep and wakefulness provides an important example of how the SCN signal is integrated with other information. Specifically, the wake-sleep circuit consists of contrasting brain centers promoting arousal and sleep. Key arousal areas are monoaminergic nuclei, such as the locus coeruleus, the raphe nuclei, and the tuberomammillary nucleus; these are activated in part by orexin-containing cells of the lateral hypothalamic area. The main sleep-promoting region is the ventrolateral 
preoptic nucleus. A detailed review of this architecture is provided by Saper et al, ${ }^{19}$ but essentially, these two regions are mutually inhibitory and function as a flip-flop switch. Many of these nuclei, such as the ventrolateral preoptic nucleus and the orexin-containing cells, receive input from the SCN. ${ }^{8,20,21}$ However, while the SCN exerts an influence, the switch does not strictly follow the 24-hour rhythm of the SCN. Rather, wake-sleep transitions respond to many additional factors, including homeostatic drive (extended periods of sleep will follow deprivation) and also external stimulation. Rapid eye movement sleep is primarily under the control of circadian rhythmicity and is normally at its peak near the end of the sleep period. Slow-wave sleep timing primarily reflects wake-sleep homeostasis. In this manner, the wake-sleep circuit integrates the SCN clock signal with many other inputs, allowing it to respond dynamically to a breadth of demands.

\section{Circadian measurement protocols and terminology}

Since circadian rhythms, the wake-sleep cycle, and other endogenous and external 24-hour oscillations are often correlated, it can be difficult to separate out their effects in relation to epilepsy. To investigate different systems in isolation, a number of studies adjust experimental protocols in order to desynchronize or eliminate certain 24-hour oscillations. Forced desynchrony protocols involve altering the period of the light-dark cycle or other external zeitgebers and cause internal rhythms to become desynchronized, allowing them to be studied independently. Forced desynchrony has been applied in human ${ }^{22}$ and animal studies. ${ }^{23}$ An alternative approach is the constant routine protocol, which completely removes variation in external factors such as daylight. ${ }^{24}$ This approach has been applied in several epilepsy studies. ${ }^{25,26}$ A review of these methods is provided by Hofstra et al..$^{27}$

While some of the studies covered in this review make use of separation protocols, many do not. In order to ensure consistent terminology, we shall only refer to 24-hour rhythms as circadian if there is strong evidence that they are truly associated with the circadian system. For cases in which a rhythm is associated with some other 24-hour phenomenon, such as the light-dark cycle, or in which the origin is not clear, we shall refer to the rhythm as a diurnal rhythm.

\section{4-hour rhythms in the brain}

The hierarchical structure of the circadian system allows for regulation of 24-hour rhythms pervasively throughout the body. It has recently been estimated that more than $10 \%$ of genes are subject to circadian regulation in mammalian peripheral tissue. ${ }^{28}$ In the brain, circadian regulation is highly pervasive as well, and 24-hour rhythms of neural activity can be detected at most recording sites using a variety of recording techniques. The pervasiveness and complexity of circadian regulation in the brain can be seen from the summary of brain regions exhibiting 24-hour oscillations, as shown in Table 1. An understanding of these interactions is useful for interpreting the interactions between epilepsy and 24-hour rhythms.

\section{Diurnal rhythms and epilepsy Bidirectional relationship}

Diurnal rhythms and epilepsy show a bidirectional relationship, with seizures showing 24-hour patterns of recurrence and epilepsy causing disruptions in 24-hour rhythms.

Understanding the first part of this relationship, the 24-hour rhythms of seizures, is imperative for designing

Table I Brain regions exhibiting 24-hour rhythms in vivo

\begin{tabular}{|c|c|c|c|}
\hline Brain region & Measurement & Species & Reference \\
\hline Accumbens nucleus & MUA & Hamster & 29 \\
\hline Anterior hypothalamus & Histamine & Rat & $30 * *$ \\
\hline \multirow[t]{2}{*}{ Caudate nucleus } & MUA & Rat & 31 \\
\hline & 5-HT, histamine, NE & Rat & 32,33 \\
\hline Caudate putamen & MUA & Hamster & 29 \\
\hline Lateral hypothalamic area & MUA & Rat & 34 \\
\hline Lateral septum & MUA & Hamster & 29 \\
\hline \multirow[t]{2}{*}{ Locus coeruleus } & SUA & Rat & 35 \\
\hline & 5-HT, NE & Rat & 36 \\
\hline \multirow{3}{*}{$\begin{array}{l}\text { Medial and dorsal raphe } \\
\text { nuclei }\end{array}$} & MUA & Rat & 31 \\
\hline & $5-\mathrm{HT}$ & Rat & $37^{\#}$ \\
\hline & 5-HT, NE & Rat & 36 \\
\hline Medial preoptic region & MUA & Hamster & 29 \\
\hline Medial septum & MUA & Hamster & 29 \\
\hline Midbrain & 5-HT, histamine, NE & Rat & 32,33 \\
\hline \multicolumn{4}{|l|}{ formation } \\
\hline Stria medullaris & MUA & Hamster & 29 \\
\hline Substantia nigra & MUA & Rat & 34 \\
\hline \multirow[t]{3}{*}{ Suprachiasmatic nucleus } & MUA & Rat & 31 \\
\hline & MUA & Rat & 34 \\
\hline & MUA & Hamster & 29 \\
\hline Thalamus & MUA & Rat & 34 \\
\hline $\begin{array}{l}\text { Ventrolateral thalamic } \\
\text { nucleus }\end{array}$ & MUA & Hamster & 29 \\
\hline \multirow{2}{*}{$\begin{array}{l}\text { Ventromedial } \\
\text { hypothalamic nucleus }\end{array}$} & MUA & Rat & 34 \\
\hline & MUA & Hamster & 29 \\
\hline Visual cortex & MUA & Rat & 31 \\
\hline
\end{tabular}

Notes: **Histaminergic neurons in the brain are located in the tuberomammillary nucleus of the posterior hypothalamus. However, the anterior hypothalamic area contains the highest concentration of histaminergic fibers; \#observed variation was bimodal. Abbreviations: MUA, multiunit activity; SUA, single unit activity; $5-\mathrm{HT}$, serotonin; NE, norepinephrine. 
appropriate chronotherapies based on seizure timing. As we shall review, different types of epilepsies can also show vastly different times for peak seizure activity, a phenomenon that has been previously proposed to have diagnostic potential. ${ }^{8}$

Reciprocally, the chronic epilepsy state can impair both sleep and 24-hour rhythms. This can occur in the form of abnormal sleep architecture and also disrupted amplitude, phase, and complexity of 24-hour oscillations in a variety of biological signals.

\section{Effect of diurnal rhythms on epileptic seizures}

There are many daily rhythms present in the body. Their origin and function can be traced to the extrinsic 24-hour light-dark cycle, which determines optimal times for resting, feeding, and procreating. Most organisms on the planet entrain to this daily cycle. Mammals show 24-hour rhythms in their globally regulated functions, including digestive activity, wake-sleep state, rest-activity cycle, and core body temperature (CBT). ${ }^{38}$ When the circadian system is functioning properly, it serves to coordinate these 24-hour processes.

There is strong evidence that the wake-sleep cycle can influence epileptic seizures, and this relationship is the subject of other reviews. ${ }^{2,39}$ Thus, when discussing the role of circadian rhythms on seizure activity, it becomes important to separate the influence of the wake-sleep cycle from other processes.

A number of studies have addressed this problem and suggest that, in addition to sleep, the circadian timing system can play a direct role in regulating seizures. First, it has been shown in a rat model of spontaneous limbic epilepsy ${ }^{40,41}$ that the 24-hour rhythm of seizures appeared for animals kept in a controlled light-dark environment and persisted when animals were kept in constant darkness. ${ }^{25}$ Furthermore, while seizures occurred predominantly during periods of inactivity for animals in a light-dark environment, this state preference was lost upon transition to constant darkness. This suggests that the 24-rhythm of seizures in constant darkness was not driven by changes in activity state.

Additionally, several studies have investigated the timing of peak seizure activity, and have shown that it varies depending on location of seizure focus. In particular, a recent clinical study examined a medically refractory epilepsy patient with two separate epileptic foci, one limbic and one parietal. This investigation showed that, although seizures from both foci occurred with 24-hour periodicity, these rhythms were out of phase with each other, with temporal seizures peaking near noon and parietal seizures peaking in the early morning hours. ${ }^{42} \mathrm{~A}$ review has summarized multiple studies on focal epilepsy, showing a relationship between the location of seizure focus and the timing of peak seizure activity. ${ }^{43}$ One recent study suggests that age and seizure semiology can also influence the diurnal patterns of epileptic seizures. ${ }^{44}$

Finally, studies have compared human mesial temporal lobe epilepsy (TLE) with a similar epilepsy model ${ }^{40,41}$ in rats. It was shown that the 24-hour seizure rhythms in rats and humans were in phase, both peaking in the early afternoon, despite the fact that humans are diurnal (sleeping at night) and rats are nocturnal. ${ }^{45}$ Although the wake-sleep cycle is inverted across nocturnal and diurnal organisms, many components of the circadian system are phase-conserved across these species. For example, melatonin, one of the primary hormonal outputs of the circadian system, is secreted at night for both nocturnal and diurnal organisms. ${ }^{6}$ It is interesting that one recent study examined seizure rhythms in pilocarpineinduced status epilepticus and found no significant correlation of seizure frequency with circadian rhythms. ${ }^{46}$ Thus, while the 24-hour rhythms of epileptic seizures have been clearly established, the contributions of underlying systems to these are complex and not fully understood.

Traditionally it is thought that 24-hour seizure rhythms result from modulation of the epileptic brain region by neuromodulators and/or neurohormones that are released with 24-hour rhythmicity. ${ }^{6}$ Thus, similar to how certain behavioral states exhibit favorable conditions for seizure formation, ${ }^{47}$ certain times of day may also contain levels of neuromodulators that promote the epileptic brain to be most prone to seize. It is well established that the release of many neuromodulators and neurohormones is regulated on a 24-hour basis (Table 1); additionally, many of these also have the ability to promote or inhibit epileptic seizures. ${ }^{48,49}$ An example of such a neurohormone is melatonin, which is released primarily at night. Although it is a putative anticonvulsant, it has also been shown to promote epileptiform activity in slice..$^{50}$ Furthermore, as mentioned above, melatonin is a hormone that is phase-conserved across nocturnal and diurnal species. Other compounds, such as vasopressin and hormones of the hypothalamic-pituitary-adrenal axis, have been proposed to play roles in the 24-hour rhythm of seizures. ${ }^{6}$ One study suggests that daily variation in audiogenic seizure susceptibility is related to 5-HT and norepinephrine levels. ${ }^{51}$ More recent studies have also hypothesized a role for molecular mechanisms in seizure regulation. ${ }^{52}$ However, as yet, a causal linkage between these neuromodulators, neural activity, and seizure 24-hour rhythms has not been demonstrated. 


\section{Effect of epilepsy on wake-sleep cycle}

Epilepsy has a significant impact on sleep and the wakesleep cycle. ${ }^{1-5,53}$ Changes in total sleep time, sleep latency, and spontaneous awakenings have been found in children. ${ }^{4}$ Epilepsy may affect both the quantity and the architecture of sleep, depending on seizure type. The amount of rapid eye movement sleep is decreased by $50 \%$ in patients with primary generalized tonic-clonic seizures and as low as $41 \%$ in patients with secondarily generalized seizures. ${ }^{3} \mathrm{~A}$ recent polysomnography study in children with refractory epilepsy encephalopathies showed altered sleep, respiratory, and limb movement patterns relative to controls. ${ }^{53}$ Not all types of epilepsy have effects on sleep duration or architecture. It is interesting that in benign focal epilepsy, a disorder with no apparent impairment of cognitive function, the sleep pattern is largely unimpaired despite nocturnal seizures. ${ }^{5}$

\section{Effect of epilepsy on circadian rhythms}

A fundamental question in circadian research is how certain diseases affect the circadian system and impair its ability to coordinate 24-hour rhythms. Studies suggest that severe neurodegenerative disorders, including Alzheimer's disease, Huntington's disease, Parkinson's disease, and multiple sclerosis, can affect circadian/sleep regulatory structures and can disrupt 24-hour rhythms. ${ }^{9,54}$ There is growing evidence that epilepsy too can affect the circadian system; however, in part due to the wide variety of epilepsy syndromes, these changes are less concretely defined.

There are two distinct avenues by which circadian rhythms might become disturbed in epilepsy. First, the acute effects of epileptic seizures might promote transient circadian perturbations. This is supported by a study on daily rhythms of CBT, a surrogate marker for circadian regulation in mammals. ${ }^{27}$ This study showed that CBT rhythms experienced slight and transient phase shifts following seizures in hippocampal kindled animals. ${ }^{55}$

Second, permanent structural changes in the brain associated with the chronic epilepsy state may permanently alter circadian rhythms. ${ }^{25}$ This is suggested by studies on globally regulated functions, which have shown anomalies in cardiovascular parameters ${ }^{56,57}$ and melatonin release. ${ }^{58,59}$ These findings are highly dependent on epilepsy syndrome and a comprehensive review is provided by Hofstra et al. ${ }^{7}$ Altered 24-hour rhythms of behavioral activity have been observed after pilocarpine-induced status epilepticus, but it was suggested that this might be caused by postictal hyperactivity; ${ }^{60}$ a later study on absence epilepsy by the same group found significant changes in amplitude but not in the phase of total behavioral movement. ${ }^{61}$ Likewise, a study on CBT rhythms, a surrogate marker for SCN rhythms, found an increase in complexity of CBT oscillations, but no changes in CBT phase in animals with TLE induced by status epilepticus. ${ }^{62}$ Together, these studies suggest that the phase of globally regulated functions remains generally unchanged in TLE animal models; however, other properties of the signal may be altered and seizures may induce transient perturbations. In the case of MeCP2-deficient mice, which seize spontaneously and serve as a model for Rett syndrome, more severe symptoms result, including abnormal daily rhythms of cortical delta activity, CBT, and mobility. ${ }^{63}$

A variety of brain regions have been proposed to underlie these changes. For example, reported cell loss in the dorsomedial hypothalamus, a region relevant for sleep regulation, has been suggested as the cause for abnormalities in the wake-sleep cycle. ${ }^{1}$ Likewise, changes in the medial preoptic nucleus reported by Quigg et al ${ }^{62}$ may underlie the increased complexity in CBT rhythms. There are likely other brain structures involved in the regulation of circadian rhythms that may be altered in the epileptic state and that remain to be identified. In summary, preliminary evidence supports the notion that the circadian system is altered in epilepsy; however, unlike the case for neurodegenerative diseases, it is not clear exactly which mechanisms and brain regions are involved. This results partly from the large number of epilepsy syndromes, and also from epilepsy's nature of affecting a wide range of brain structures. ${ }^{64}$

\section{Effects of epilepsy on 24-hour rhythms of brain activity}

Several recent studies have also focused on 24-hour rhythms of local brain activity. Disruption of 24-hour rhythms local to the site of epilepsy could potentially exacerbate seizures and other epilepsy symptoms. The first study examined electroencephalographic spiking activity in rats with TLE induced by status epilepticus. It showed that these spikes exhibited a 24-hour rhythm that shifted phase by $>10$ hours following status epilepticus injury ${ }^{65}$ Importantly, these changes occurred after injury but prior to the emergence of spontaneous seizures. A follow-up study showed that this phase shift was independent of markers for the wake-sleep cycle and CBT rhythms and, furthermore, did not occur in animals that were stimulated with status epilepticus but failed to develop spontaneous seizures (Figure 1) ${ }^{66}$ It was proposed that altered 24-hour rhythmic input from the medial septum might be responsible for this phase shift. ${ }^{66}$ In a separate study, Matzen et al used single-pulse and paired-pulse response 


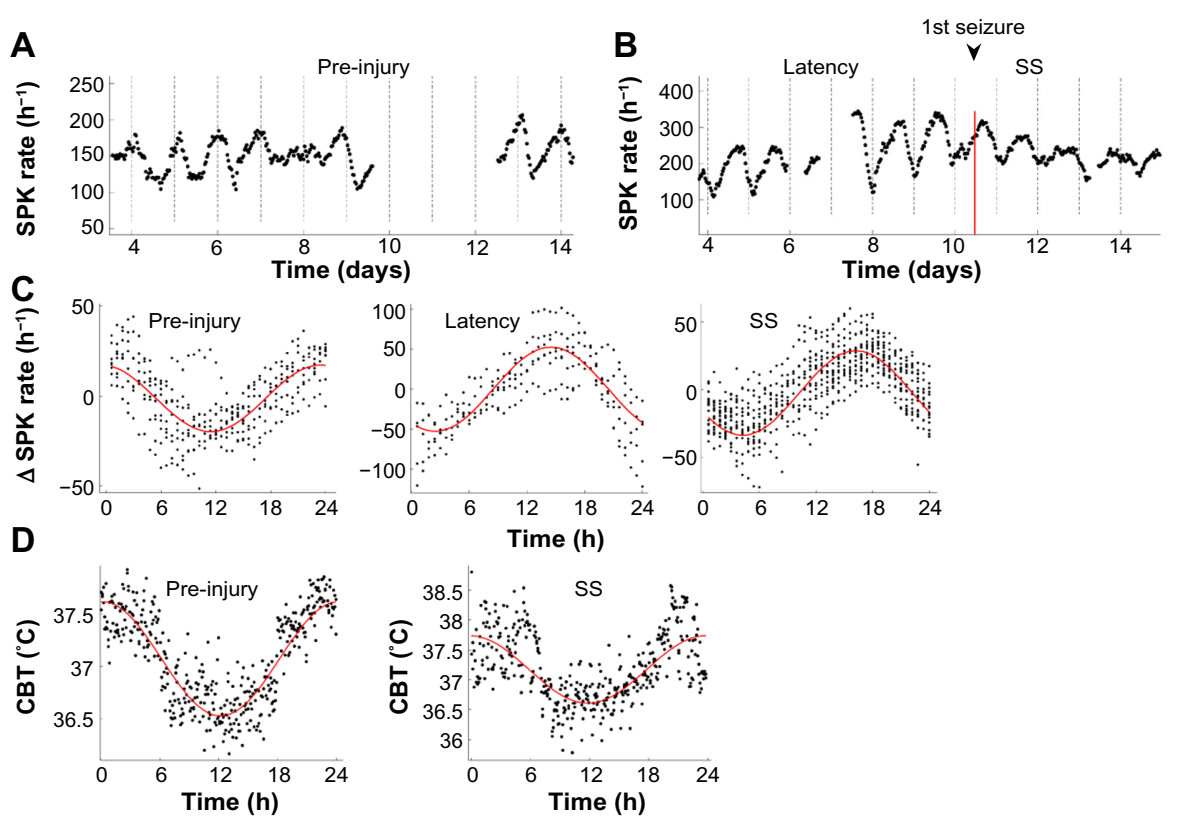

Figure I Phase shift in the diurnal rhythm of SPK.

Notes: (A and B) Chronic tracking of SPK rates for preinjury, latency, and spontaneously seizing stages of epileptogenesis for a single rat. Dot-dashed vertical lines correspond to midnight. (C) Time series were combined into a 24-hour time windows (modulo 24) revealing a post-injury phase shift that occurs during the latency period, before spontaneous seizures appear. (D) Circadian rhythm of CBT are shown. There was no observed phase shift after injury, although the variability of the signal did increase. Copyright (C) 2013, The American Physiological Society. Adapted from Stanley DA, Talathi SS, Parekh MB, et al. Phase shift in the 24-hour rhythm of hippocampal EEG spiking activity in a rat model of temporal lobe epilepsy. J Neurophysiol. 2013;1 10(5): 1070-1086. ${ }^{66}$

Abbreviations: CBT, core body temperature; h, hours; SPK, hippocampal spiking activity; SS, spontaneously seizing.

measurements to suggest that hippocampal excitation was enhanced during the day and that inhibition was enhanced at night in an animal epilepsy model ${ }^{67}$ These changes, they proposed, might be caused by altered hypothalamic-regulated hormone release. Together, these findings suggest that local 24-hour regulation in the hippocampus is disrupted in TLE.

\section{Effect of epilepsy chronotype}

Individual timing of daily activities and sleep varies considerably throughout the population. This is referred to as an individual's chronotype. Chronotype is often characterized by the Morningness Eveningness Questionnaire (MEQ), which differentiates morning-type and evening-type individuals. ${ }^{68}$ MEQ may also be a reasonable predictor of endogenous circadian phase. ${ }^{69}$

Several studies have investigated chronotype and have shown associations between chronotype and epilepsy syndrome and also between chronotype and the timing of taking AEDs. ${ }^{7,70,71}$

A recent chronotype study ${ }^{72}$ surveyed 200 epileptics using both the MEQ and the Munich Chronotype Questionnaire. ${ }^{73}$ They found significant differences in chronotype between epileptics and healthy controls. However, they did not find significant differences among subgroups of patients with well defined epilepsy syndromes, despite the fact that they exhibit seizures with different diurnal patterns. This supports the notion that the epileptic state, rather than timing of individual seizures, has an effect on chronotype. ${ }^{72}$

\section{Effect of epilepsy on reproductive hormones}

Many reproductive hormones of the hypothalamicpituitary-gonadal axis show 24-hour periodicity, including gonadotropin-releasing hormone, luteinizing hormone, prolactin, and follicle-stimulating hormone. ${ }^{74-76}$ Both generalized and partial seizures can have effects on these reproductive hormones. ${ }^{77,78}$ It is hypothesized the underlying mechanism might begin with activation of gonadotropinreleasing hormone-secreting neurons in the hypothalamus. These neurons receive significant innervation from limbic brain regions commonly associated with TLE, particularly the amygdala. Gonadotropin-releasing hormone secretion could then trigger pulsatile release of luteinizing hormone, which would in turn promote release of pituitary hormones. It has been proposed that altered pulsatile release patterns of luteinizing hormone could be a diagnostic marker of epilepsy. ${ }^{77}$ Such alterations in hormone release may account for the well documented effects of epilepsy on reproductive health in men and women, ${ }^{79-81}$ which in turn may relate to additional exacerbation of seizures. ${ }^{82,83}$ 


\section{Chronopharmacology and epilepsy Overview of chronopharmacology}

Chronopharmacology, briefly, is the optimization of drug delivery timing through the consideration of natural and pathological bodily rhythms. The concept was first outlined by Alain Reinberg and Franz Halberg in $1971^{84}$ and has seen renewed interest in recent years spurred by a number of advances in circadian research.

There are several principles underlying chronopharmacological drug delivery. The first is chronobiology, which is the study of biological rhythms. There are many types of biological rhythms spanning many time scales, ranging from millisecond-scale oscillations of nerve cells, to hourly ultradian rhythms, to weekly or monthly infradian rhythms. For the field of chronopharmacology, 24-hour circadian rhythms are of key relevance. It has been shown that many pathologies possess clear 24-hour oscillations. ${ }^{6}, 10$ Thus, dosing drugs to be present at times of peak pathological activity can be an effective treatment strategy.

A second aspect of chronopharmacology pertains to the time scales of drug processing by the body. Traditional drug dosing involves consideration of many bodily processes, including absorption, metabolism, and excretion. It is the collection of these processes that determines the time course of drug availability within the biological tissue. The collection of these processes together and their influence on drug availability is referred to as pharmacokinetics. As shall be discussed, research has shown that the body's processing of many classes of drugs has strong circadian dependence. Chronopharmacokinetics refers to this influence of chronobiological rhythms on drug processing. These rhythms can have a profound influence on determining optimal dosing schedules.

A third and less studied aspect of chronopharmacology is the interaction between biological rhythms and pharmaceutical action. Biological rhythms can interact with pharmaceutical activity in two ways. First, drugs can exhibit diurnal variation in their efficacy and in their side effects. Secondly, compounds such as melatonin and valproate can also influence and induce phase shifts in circadian rhythms ${ }^{85,86}$ While this can affect biological rhythms in a negative way, such drugs can also be used strategically. For example, a number of diseases, including epilepsy, Parkinson's disease, and Alzheimer's disease, ${ }^{9,54}$ can affect and impair the circadian timing system, and these drugs, timed appropriately, might be useful for correcting these circadian disorders. Chronopharmacodynamics is the study of these phenomena, describing the effects of drugs on the body in relation to endogenous biological rhythms.
Thus, chronopharmacology can be defined as the delivery of pharmaceutical agents according to the chronobiology of the disease and according to the unique chronopharmacokinetics and chronopharmacodynamics of the drug. Chronopharmacology can be considered a central tool within the more general area of chronotherapy, for which the treatments may not be pharmaceutical in nature but rather might involve other influences, such as light therapy. The specific application of chronotherapy to epilepsy can be referred to as chrono-epileptology. ${ }^{8,87}$

Chronopharmacology and chronotherapy approaches may benefit from personalization to the patient's chronotype. As discussed above, chronotype can be assessed by questionnaires, such as the MEQ and Munich Chronotype Questionnaire, described above. Additional more direct measures of a patient's endogenous 24-hour rhythms are available, including dim light melatonin onset, actigraphy, CBT, sleep parameters, and cortisol production., ${ }^{7,27}$

A number of prior papers provide comprehensive reviews of the subject of chronopharmacology. The concept was first introduced by Reinberg et al,${ }^{84}$ and a number of reviews in the following years outline new technologies and clinical progress in relation to a variety of pathologies. ${ }^{12,88}$ Several reviews are specifically devoted to chronopharmacology and the interaction between circadian rhythms and epilepsy. ${ }^{8,89}$ Dallmann et al focus specifically on molecular mechanisms of the circadian clocks and implications for chronotherapy. ${ }^{90}$

\section{Chronobiological and chronopharmacokinetic measures}

The phase of a circadian rhythm is usually measured based on the trough or crest of a biological rhythm. Estimations of circadian phase and amplitude are obtained from cosinor analysis. This is a process that involves fitting a circadian time series $\left(T_{i}, X_{i}\right)$ collected over multiple days with a sinusoidal function of the form $f(t)=A_{0} * \cos \left(2 \pi\left(t-t_{0}\right) / D\right)$, where $\mathrm{D}=24$ hours if the units of $t$ are hours. The estimates of parameters $A_{0}$ and $t_{0}$ can be obtained by the method least squares, for which a solution via normal equations is available. ${ }^{91}$ The parameter $t_{0}$, which is the circadian time of maximal activity in the signal, is referred to as the acrophase. Additionally, statistical tests for differences in $A_{0}$ and $t_{0}$ across populations have been derived. ${ }^{91}$ Prior to applying least squares, baseline trends may be removed from the time series $\left(T_{i}, X_{i}\right)$. This may involve simply high pass filtering or baseline estimation. ${ }^{65,66}$

For assessing chronopharmacokinetics, there are several common parameters used to measure drug concentration. 
These include peak concentration, time from dosing to peak concentration, area under the concentration curve, and duration of action. ${ }^{12,89,92}$

\section{Prior applications of chronotherapy}

In this section, we present examples of successful applications of chronotherapy to a variety of medical conditions. Common chronopharmacological strategies include optimizing drug delivery timing for peak disease activity; optimizing for daily changes in drug absorption kinetics; and optimizing for daily rhythms in drug effectiveness and side effects. Examples of prior investigations can serve as templates for future application of chronotherapy to epilepsy.

Many respiratory afflictions, including allergic rhinitis and bronchial asthma, show clear 24-hour oscillations. ${ }^{92,93}$ These oscillations peak primarily in the night-time, which is a common experience for sufferers of hayfever, and can lead to differential dosing opportunities. For example, a large multicenter clinical study found that the therapeutic effect of mequitazine, a histamine $\mathrm{H}_{1}$ receptor antagonist, was optimized when the bulk of the dosage was taken in the evening. ${ }^{94,95}$ This increased effectiveness was likely due to both the night-time prevalence of allergic rhinitis and also the drug's chronopharmacokinetic properties. In particular, Reinberg et al showed that histamine $\mathrm{H}_{1}$ receptor antagonists had a longer duration of action in the morning ( $7 \mathrm{am})$, but a higher peak concentration and shorter time from dosing to peak concentration in the evening $(7 \mathrm{pm}) .{ }^{95-98}$

In the case of bronchial asthma, theophylline and $\beta_{2}$-agonists are commonly used as treatment and these have shown chronotherapeutic effectiveness when administered in pulsatile form. ${ }^{99,100}$ Pulsatile drug tablets typically have multiple layers that dissolve at different stages of digestion, releasing portions of the drug in pulses typically separated by 6 hours. Pulsatile-release drugs taken in the evening can be used to treat early morning asthma attacks, which are difficult to target due to the lifetime of conventional drug capsules. The effectiveness of this approach has been assessed in several studies. ${ }^{101-103}$

Additionally, chronotherapy has shown promise in clinical studies for a number of other conditions, including cancer and cardiovascular disease. ${ }^{10,90}$ In particular, anticancer drugs must operate within a specific range, so as to be toxic to cancer cells but not to other cells in the body. This range can vary significantly throughout the day and can be leveraged by chronotherapy treatments..$^{90}$ Chronotherapy has shown promise in a number of randomized multicenter trials, particularly in the case of metastatic colorectal cancer. ${ }^{104}$
Chronotherapy has yet to be applied extensively to conditions of the brain; however, in addition to epilepsy, a number of neurological disorders show circadian dependence of symptoms and/or disruption of circadian rhythms. Thus, such findings have spawned a number of reviews addressing the possibilities of chronotherapy for specific brain illnesses, ${ }^{9}$ including Alzheimer's disease, ${ }^{105}$ Parkinson's disease, ${ }^{106}$ multiple sclerosis, ${ }^{107,108}$ and Huntington's disease. ${ }^{109,110}$ In the case of multiple sclerosis, early clinical trials have suggested that treatment with corticosteroids benefits from chronotherapy by focusing treatment at night. ${ }^{108}$ Likewise, combined melatonin and bright light treatments were effective at alleviating daytime somnolence in institutionalized Alzheimer's patients. ${ }^{111}$

\section{Chronopharmacokinetics of antiepileptic drugs}

A comprehensive review of chronopharmacokinetics and chronopharmacodynamics in relation to epilepsy is provided by Ramgopal et al. ${ }^{89}$ As defined above, chronopharmacokinetics refers to daily rhythms in drug processing; multiple antiepileptic medications have been evaluated from this standpoint. In particular, the anticonvulsant valproate has shown 24-hour variations in absorption, ${ }^{112}$ distribution, ${ }^{113}$ and excretion. ${ }^{114}$ Volunteers undergoing constant infusion of midazolam showed daily changes in drug concentration, with plasma levels of midazolam being slightly higher at night. ${ }^{115}$ Healthy volunteers given oral doses of diazepam twice daily showed higher levels of diazepam after the morning dose than after the evening dose. ${ }^{116}$ These findings may be driven by a number of factors, including meal schedule, meal content and, more directly, plasma protein levels, which can influence drug binding. ${ }^{89}$ Considering the concentration time courses of AEDs can be relevant for designing dosing paradigms that target times of maximal seizure likelihood. We have included a table summarizing the half-lives of common AEDs (Table 2), and detailed reviews of AED pharmacokinetics are provided by Perucca ${ }^{117}$ and Pastalos. ${ }^{118}$

\section{Chronopharmacodynamics and phase shifting of antiepileptic drugs}

Epilepsy medications can also influence bodily processes in a 24-hour fashion. In particular, drug side effects might be more pronounced at certain times of day. For example, a mouse study showed that valproate exhibits toxicity with 24-hour periodicity, peaking in the second half of the rest span for mice. ${ }^{119}$ This corresponds to the second half of the night for humans. AEDs can also induce phase shifts and other 
Table 2 Half-lives of common antiepileptic drugs

\begin{tabular}{|c|c|c|}
\hline $\begin{array}{l}\text { Antiepileptic } \\
\text { drug name }\end{array}$ & $\begin{array}{l}\text { Adult half-life } \\
\text { (hours) }\end{array}$ & References \\
\hline Carbamazepine & $\begin{array}{l}\text { I8-65; 10-20 after } \\
\text { multiple doses }\end{array}$ & 118,139 \\
\hline Diazepam & $\begin{array}{l}21-70 ; 40-100 \text { with } \\
\text { contribution from } \\
\text { active metabolites }\end{array}$ & $|40-| 44$ \\
\hline Ethosuximide (Zarontin ${ }^{\circledR}$ ) & $40-60$ & 118,145 \\
\hline Lacosamide $\left(\right.$ Vimpat $\left.^{\circledR}\right)$ & $12-16$ & 146,147 \\
\hline Lamotrigine $\left(\right.$ Lamictal $\left.^{\otimes}\right)$ & $23-37$ & 148,149 \\
\hline Levetiracetam & $6-8$ & 118,150 \\
\hline Lorazepam & $7-26$ & $143,151,152$ \\
\hline Midazolam & I-6; I for active metabolites & 143,153 \\
\hline Oxcarbazepine & $\begin{array}{l}\text { I-5; 7-20 for active } \\
\text { metabolites }\end{array}$ & 118,154 \\
\hline Phenobarbital & $70-140$ & 118,155 \\
\hline Phenytoin & $7-42$ & $118,156,157$ \\
\hline Topiramate & $19-25$ & 118,158 \\
\hline Valproate & $9-16$ & 118,159 \\
\hline
\end{tabular}

disturbances in sleep and circadian rhythms. Diazepam was shown to alter the phase of the circadian clock expression in zebrafish ${ }^{120}$ and also to inhibit melatonin production in the rat pineal gland. ${ }^{121}$ Both diazepam and melatonin were found to alter the balance of circadian entrainment in a forced desynchrony study ${ }^{122}$ and melatonin is commonly used to induce phase shifts in the SCN rhythm. ${ }^{85}$ Valproate has been investigated for circadian effects and has been shown to alter the duration of the circadian period in Drosophilia ${ }^{123}$ and also in mouse and human fibroblasts. ${ }^{86}$ Lastly, sleep architecture disturbances are associated with multiple AEDs. ${ }^{124,125}$

As discussed above, 24-hour rhythm anomalies are endogenously present in several epilepsy syndromes. They have also been reported in patients undergoing epilepsy treatment. ${ }^{7}$ It is possible that the chronopharmacodynamic effects of medications, described above, contribute to circadian rhythm dysfunction in epileptic patients.

\section{Opportunities for epilepsy}

As we have seen, epileptic seizures commonly follow a night-time or daytime pattern. These patterns may be related to internal biological clocks, time of day, and wakefulness and sleep states. A patient's daily seizure pattern can be estimated from patient diaries and video electroencephalographic recordings, combined with prior knowledge from the population having the same epilepsy syndrome.

An understanding of the time of day or month when a person is most likely to seize can have significant implications for the individual and can help to guide treatment. For instance, adjusting to a higher night-time dose of antiepileptic medication may potentially alleviate medication-related sleepiness while improving control of night-time seizures. ${ }^{126,127}$ Likewise, pharmacodynamic parameters of certain epilepsy medications, such as valproate, ${ }^{127}$ show 24 -hour rhythmicity in their side effects and this can present therapeutic opportunities.

Other treatment strategies, such as time-released devices or brain stimulation, could be based on the circadian clock. Complex partial seizures may be mildly reduced by increasing the individual's exposure to bright light. ${ }^{128,129}$

AEDs $^{85,86,120-124}$ and chronic epilepsy ${ }^{62,65-67}$ may disrupt endogenous diurnal rhythms. Such disruptions may be identified either through clinical assessment of circadian markers or through personal sleep diaries. Treatment paradigms that aim to either alleviate or actively correct for circadian disruption may be effective at reducing seizures and epilepsy symptoms. In particular, differential dosing of drugs might be tuned to alleviate circadian disorganization associated with AEDs. Likewise, judicious and personalized application of melatonin, light therapy, or other phase-resetting zeitgebers might assist with correcting misaligned endogenous circadian rhythms.

\section{Current and emerging chronotherapeutic treatments}

Current strategies for chronotherapeutics in epilepsy are based on differential dosing schedules to improve the efficacy of medication in seizure control. ${ }^{89}$

One of the earliest clinical trials of a differential dosing strategy in epilepsy based on the principles of chronotherapy was conducted by Yengnarayanan et al. ${ }^{127}$ The study was based on the premise that awakening epilepsies occur more often in the late night hours, while focal motor seizures occur more frequently in the early part of the night. As a result, the maintenance of adequate drug concentrations during such susceptible time periods may reduce seizure frequency. The authors investigated the effects of a chronotherapeutic dose schedule of phenytoin and carbamazepine in two patient groups suffering from diurnal epileptic seizures: a subtherapeutic group, ie, patients with blood serum drug levels in the subtherapeutic range (carbamazepine $<4 \mu \mathrm{g} / \mathrm{mL}$, phenytoin $<10 \mu \mathrm{g} / \mathrm{mL}$ ) and a toxic group, ie, patients with blood serum drug levels in the toxic range (carbamazepine $>8 \mu \mathrm{g} / \mathrm{mL}$, phenytoin $>20 \mu \mathrm{g} / \mathrm{mL}$ ). Of the 103 patients in the subtherapeutic group, 51 were controls (STG-I) for whom the total medication dose was constant and no change in the timing of drug administration was allowed; in the remaining 52 patients (STG-II), the total dose of medication was again kept 
constant, but the majority of the dose was given at $8 \mathrm{pm}$. Of the 62 patients in the toxic group, 50\% (TG-I) received a reduced dosage of medication without any alteration in the timing of the dose, while the remaining 50\% (TG-II) received a reduced dosage as well as timing of the majority of the dose to be at $8 \mathrm{pm}$. The authors reported that the majority of the patients in the STG-II group exhibited therapeutic drug levels and better seizure control by the end of the fourth week of treatment. Furthermore, a significantly large number of patients in the TG-II group as compared with those in the TG-I group showed improved drug tolerance. These findings suggest that a chronotherapeutic dosing schedule can improve the response of diurnally active epileptic patients not responding to standard doses, achieve therapeutic drug levels, and reduce toxic manifestations in those with drug concentrations beyond the therapeutic range.

A more targeted differential dosing strategy in patients suffering from nocturnal or early-morning seizures refractory to conventional AED therapy was reported in a pilot trial published by Guilhoto et al. ${ }^{126}$ A total of 18 patients were treated with an appropriate AED in a schedule for which the evening dose was twice the morning dose, keeping the total dose of medication constant. Eleven patients of the 18 patients became seizure-free after a mean follow-up period of 5.3 months and four patients exhibited a $75 \%-90 \%$ reduction of seizures. This study indicates that even in patients who are initially unresponsive to conventional AED treatment, a differential dosing schedule based on the principles of chronotherapy can provide improved seizure control.

Emerging chronotherapeutic approaches involve looking at other avenues, such as melatonin regulation, light therapy, and closed-loop treatment protocols. In particular, melatonin has been reported to increase following convulsive seizures, an effect that has been suggested to be related to the anticonvulsant properties of melatonin. ${ }^{130}$ Melatonin has also been used as a chronotherapeutic medication to adjust circadian rhythms, and may therefore have a role in the alignment of circadian rhythms in epileptic patients. ${ }^{131}$ A recent review of clinical trials on melatonin as an add-on treatment for epilepsy failed to identify any conclusive evidence for the role of melatonin in reducing seizure frequency or improving quality of life in patients with epilepsy. ${ }^{132}$ This suggests that more systematic investigations are required to evaluate the efficacy of melatonin in epilepsy.

Another emerging chronotherapeutic treatment strategy involves the use of light therapy to control seizures. From a neurobiological perspective, there are three strands of evidence in the literature that suggest light therapy may provide an effective treatment for some patients with epilepsy: sunlight is important in the endogenous production and regulation of melatonin and vitamin $\mathrm{D}$, both of which influence seizure thresholds; seizure frequencies increase in the winter and on dull overcast days; and light therapy is an established medical treatment for depression. ${ }^{128} \mathrm{~A}$ recent double-blind, randomized controlled trial evaluating the efficacy of light therapy on seizure frequency in patients with intractable focal epilepsy found that both high (10,000 Lux) and low (2,000 Lux) intensity bright light therapy were effective in mildly reducing seizure frequency in patients with hippocampal sclerosis. ${ }^{129}$ The effects on patients with other focal epilepsies were not significant.

Finally, automated seizure detection systems allow for continuous monitoring of seizure activity and may provide valuable data for identifying periods of seizure clusters in individual patients. ${ }^{133-135}$ These data, in addition to recent progress in the technology for localized delivery systems, such as responsive neurostimulation ${ }^{133}$ and use of targeted drug delivery systems, ${ }^{136}$ may allow for highly targeted and specific chronotherapeutic dosing strategies that are tuned to individual seizures, in line with endogenous rhythms in patients. Thus, while more studies are needed, the available evidence suggests that chronotherapy may allow for better control of intractable seizures.

\section{Implications for enhanced patient care Benefits of tracking seizure rhythms}

Chronotherapy can improve patient care through a number of avenues. First, differential dosing of therapy based on a patient's 24-hour seizure rhythms can improve the efficacy of therapy and reduce side effects. In particular, if receptors are maximally activated only at peak seizure times, this could reduce drug tolerance and side effects. As reported by Guilhoto et al, ${ }^{126}$ a subset of patients who were initially unresponsive to AEDs was assisted by a differential dosing paradigm. Additionally, as discussed above, side effects of certain pharmaceuticals may also show 24-hour rhythmicity. ${ }^{119}$ Thus, it may be possible to reduce side effects by using differential dosing that caters to these rhythms.

Knowledge of seizure rhythms can aid in early diagnosis of epilepsy. In a recent review on focal epilepsies, distinct peak seizure times were reported for temporal ( $4 \mathrm{pm}$ to $5 \mathrm{pm}$ ), frontal (5 am to $7 \mathrm{am}$ ), and occipital seizures (7 pm), and bimodal peaks for parietal and mesial temporal onset seizures. ${ }^{43}$ Therefore, information on peak seizure time might also provide diagnostic constraints, suggesting certain sites of seizure onset and underlying syndromes. ${ }^{8}$ However, 
personalization to the chronotype of the individual patient is also likely to be relevant. ${ }^{7,70}$

\section{Benefits of treating circadian and sleep disruption}

Effects of epilepsy-associated circadian disruption have been less studied, but may have important consequences for patient well-being. As discussed above, studies have shown that altered amplitude, phase, and waveform in 24-hour rhythms can appear in various brain regions and in globally regulated functions. It is well established that disrupted daily rhythms can have pathological implications, including emotional disorders, cognitive deficiency, impaired resistance to disease, and increased risk of cardiovascular disease and cancer., ${ }^{9,10}$ Studies in shift workers have shown increased risk of diabetes, ulcers, cancer, and cardiovascular disease, and chronic jet lag has been demonstrated to produce temporal lobe atrophy and cognitive defects. ${ }^{137,138}$ Disorganized circadian rhythms may even have a direct effect on promoting seizures, as has been suggested recently in absence epilepsy. ${ }^{11}$ Despite these possibilities, however, a causal link has not yet been demonstrated between epilepsy-associated circadian disruption and epilepsy symptoms. Furthermore, the relationships between pharmaceuticals and circadian disruption in epilepsy are largely unknown. Nonetheless, in the light of recent findings regarding circadian disruption in epilepsy, chronotherapies that aim to correct circadian dysfunction may be a simple and untapped avenue for treating epilepsy-related symptoms.

\section{Conclusion}

Progress over the past two decades in characterizing the relationship between epilepsy and circadian rhythms has created opportunities for applications of chronotherapeutic techniques to the treatment of epilepsy. The appeal of these techniques is that improvements in patient care can be obtained, with the only cost being personalization of the therapy to the patient's circadian rhythm. With the increased prevalence of automated monitoring devices and electronic diaries for seizure tracking, such personalization is becoming more prevalent and accessible. Conversely, recognition of the negative effects of circadian perturbation in epilepsy, combined with the ability to detect and correct these perturbations, may lead to improved patient quality of life.

\section{Acknowledgment}

This work was supported in part by Collaborative Research in Computational Neuroscience: Evolution into Epilepsy, National Institutes of Health grant RO10EB004752 (PRC); a BJ and Eve Wilder Endowment (PRC, SST); and the Children's Miracle Network (PRC, SST).

\section{Disclosure}

The authors report no conflicts of interest in this work.

\section{References}

1. Bastlund JF, Jennum P, Mohapel P, Penschuck S, Watson WP Spontaneous epileptic rats show changes in sleep architecture and hypothalamic pathology. Epilepsia. 2005;46(6):934-938.

2. Shouse MN, da Silva AM, Sammaritano M. Circadian rhythm, sleep, and epilepsy. J Clin Neurophysiol. 1996;13(1):32-50.

3. Besset A. Influence of generalized seizures on sleep organization. In: Sterman M, Shouse MN, Passouant P, editors. Sleep and Epilepsy. New York, NY, USA: Academic Press; 1982.

4. Sterman M, Shouse MN, Passouant P. Sleep and Epilepsy. New York, NY, USA: Academic Press; 1982.

5. Clemens B, Oláh R. Sleep studies in benign epilepsy of childhood with rolandic spikes. I. Sleep pathology. Epilepsia. 1987;28(1):20-23.

6. Quigg M. Circadian rhythms: interactions with seizures and epilepsy. Epilepsy Res. 2000;42(1):43-55.

7. Hofstra WA, de Weerd AW. The circadian rhythm and its interaction with human epilepsy: a review of literature. Sleep Med Rev. 2009;13(6): 413-420.

8. Loddenkemper T, Lockley SW, Kaleyias J, Kothare SV. Chronobiology of epilepsy: diagnostic and therapeutic implications of chronoepileptology. J Clin Neurophysiol. 2011;28(2):146-153.

9. Wulff K, Gatti S, Wettstein JG, Foster RG. Sleep and circadian rhythm disruption in psychiatric and neurodegenerative disease. Nat Rev Neurosci. 2010;11(8):589-599.

10. Hastings MH, Reddy AB, Maywood ES. A clockwork web: circadian timing in brain and periphery, in health and disease. Nat Rev Neurosci. 2003;4(8):649-661.

11. Smyk MK, Coenen A, Lewandowski MH, van Luijtelaar G. Internal desynchronization facilitates seizures. Epilepsia. 2012;53(9): $1511-1518$.

12. Ohdo S. Chronotherapeutic strategy: rhythm monitoring, manipulation and disruption. Adv Drug Deliv Rev. 2010;62(9-10):859-875.

13. Belle MD, Diekman CO, Forger DB, Piggins HD. Daily electrical silencing in the mammalian circadian clock. Science. 2009;326(5950): 281-284.

14. Dijk DJ, Boulos Z, Eastman CI, Lewy AJ, Campbell SS, Terman M. Light treatment for sleep disorders: consensus report. II. Basic properties of circadian physiology and sleep regulation. J Biol Rhythms. 1995; 10(2):113-125.

15. Gerstner JR, Yin JC. Circadian rhythms and memory formation. Nat Rev Neurosci. 2010;11(8):577-588.

16. Ko CH, Takahashi JS. Molecular components of the mammalian circadian clock. Hum Mol Genet. 2006;15(Spec No 2):R271-R277.

17. Guilding C, Piggins HD. Challenging the omnipotence of the suprachiasmatic timekeeper: are circadian oscillators present throughout the mammalian brain? Eur J Neurosci. 2007;25(11):3195-3216.

18. Richter HG, Torres-Farfán C, Rojas-García PP, Campino C, Torrealba F, Serón-Ferré M. The circadian timing system: making sense of day/night gene expression. Biol Res. 2004;37(1):11-28.

19. Saper CB, Scammell TE, Lu J. Hypothalamic regulation of sleep and circadian rhythms. Nature. 2005;437(7063):1257-1263.

20. Deurveilher S, Semba K. Indirect projections from the suprachiasmatic nucleus to major arousal-promoting cell groups in rat: implications for the circadian control of behavioural state. Neuroscience. 2005;130(1): 165-183.

21. Abrahamson EE, Leak RK, Moore RY. The suprachiasmatic nucleus projects to posterior hypothalamic arousal systems. Neuroreport. 2001;12(2):435-440. 
22. Dijk DJ, Czeisler CA. Contribution of the circadian pacemaker and the sleep homeostat to sleep propensity, sleep structure, electroencephalographic slow waves, and sleep spindle activity in humans. J Neurosci. 1995;15(5 Pt 1):3526-3538.

23. De La Iglesia HO, Cambras T, Diez-Noguera A. Circadian internal desynchronization: lessons from a rat. Sleep Biol Rhythms. 2008;6: 76-83.

24. Mills JN, Minors DS, Waterhouse JM. Adaptation to abrupt time shifts of the oscillator(s) controlling human circadian rhythms. J Physiol. 1978;285:455-470.

25. Quigg M, Clayburn H, Straume M, Menaker M, Bertram EH. Effects of circadian regulation and rest-activity state on spontaneous seizures in a rat model of limbic epilepsy. Epilepsia. 2000;41(5):502-509.

26. Smith VM, Baserman JN, Hagel K, Teskey GC, Antle MC. A single generalized seizure alters the amplitude, but not the phase, of the circadian activity rhythm of the hamster. Chronobiol Int. 2009;26(1):1-13.

27. Hofstra WA, de Weerd AW. How to assess circadian rhythm in humans: a review of literature. Epilepsy Behav. 2008;13(3):438-444.

28. Storch KF, Lipan O, Leykin I, et al. Extensive and divergent circadian gene expression in liver and heart. Nature. 2002;417(6884):78-83.

29. Yamazaki S, Kerbeshian MC, Hocker CG, Block GD, Menaker M. Rhythmic properties of the hamster suprachiasmatic nucleus in vivo. J Neurosci. 1998;18(24):10709-10723.

30. Mochizuki T, Yamatodani A, Okakura K, Horii A, Inagaki N, Wada H. Circadian rhythm of histamine release from the hypothalamus of freely moving rats. Physiol Behav. 1992;51(2):391-394.

31. Inouye ST, Kawamura H. Persistence of circadian rhythmicity in a mammalian hypothalamic "island" containing the suprachiasmatic nucleus. Proc Natl Acad Sci USA. 1979;76(11):5962-5966.

32. Friedman AH, Walker CA. Circadian rhythms in rat mid-brain and caudate nucleus biogenic amine levels. J Physiol. 1968;197(1):77-85.

33. Friedman AH, Walker CA. Rat brain amines, blood histamine and glucose levels in relationship to circadian changes in sleep induced by pentobarbitone sodium. J Physiol. 1969;202(1):133-146.

34. Inouye $\mathrm{ST}$. Does the ventromedial hypothalamic nucleus contain a selfsustained circadian oscillator associated with periodic feedings? Brain Res. 1983;279(1-2):53-63.

35. Aston-Jones G, Chen S, Zhu Y, Oshinsky ML. A neural circuit for circadian regulation of arousal. Nat Neurosci. 2001;4(7):732-738.

36. Agren H, Koulu M, Saavedra JM, Potter WZ, Linnoila M. Circadian covariation of norepinephrine and serotonin in the locus coeruleus and dorsal raphe nucleus in the rat. Brain Res. 1986;397(2):353-358.

37. Pinato L, Ferreira Z, Markus R, Nogueira M. Bimodal daily variation in the serotonin content in the raphe nuclei of rats. Biol Rhythm Res. 2004;35(3):245-257.

38. Beersma DG, Gordijn MC. Circadian control of the sleep-wake cycle. Physiol Behav. 2007;90(2-3):190-195.

39. Malow BA, Kushwaha R, Lin X, Morton KJ, Aldrich MS. Relationship of interictal epileptiform discharges to sleep depth in partial epilepsy. Electroencephalogr Clin Neurophysiol. 1997;102(1):20-26.

40. Lothman EW, Bertram EH, Bekenstein JW, Perlin JB. Self-sustaining limbic status epilepticus induced by 'continuous' hippocampal stimulation: electrographic and behavioral characteristics. Epilepsy Res. 1989;3(2):107-119.

41. Lothman EW, Bertram EH, Kapur J, Stringer JL. Recurrent spontaneous hippocampal seizures in the rat as a chronic sequela to limbic status epilepticus. Epilepsy Res. 1990;6(2):110-118.

42. Quigg M, Straume M. Dual epileptic foci in a single patient express distinct temporal patterns dependent on limbic versus nonlimbic brain location. Ann Neurol. 2000;48(1):117-120.

43. Mirzoev A, Bercovici E, Stewart LS, Cortez MA, Snead OC, Desrocher M. Circadian profiles of focal epileptic seizures: a need for reappraisal. Seizure. 2012;21(6):412-416.

44. Ramgopal S, Powell C, Zarowski M, Alexopoulos AV, Kothare SV, Loddenkemper T. Predicting diurnal and sleep/wake seizure patterns in paediatric patients of different ages. Epileptic Disord. 2014;16(1): $56-66$.
45. Quigg M, Straume M, Menaker M, Bertram EH. Temporal distribution of partial seizures: comparison of an animal model with human partial epilepsy. Ann Neurol. 1998;43(6):748-755.

46. Bajorat R, Wilde M, Sellmann T, Kirschstein T, Köhling R. Seizure frequency in pilocarpine-treated rats is independent of circadian rhythm. Epilepsia. 2011;52(9):e118-e122.

47. Colom LV, García-Hernández A, Castañeda MT, Perez-Cordova MG, Garrido-Sanabria ER. Septo-hippocampal networks in chronically epileptic rats: potential antiepileptic effects of theta rhythm generation. $J$ Neurophysiol. 2006;95(6):3645-3653.

48. Miller JW, Turner GM, Gray BC. Anticonvulsant effects of the experimental induction of hippocampal theta activity. Epilepsy Res. 1994;18(3):195-204.

49. Lallement G, Denoyer M, Collet A, et al. Changes in hippocampal acetylcholine and glutamate extracellular levels during soman-induced seizures: influence of septal cholinoceptive cells. Neurosci Lett. 1992;139(1):104-107.

50. Musshoff U, Speckmann EJ. Diurnal actions of melatonin on epileptic activity in hippocampal slices of rats. Life Sci. 2003;73(20): 2603-2610.

51. Schreiber RA, Schlesinger K. Circadian rhythms and seizure susceptibility: effects of manipulations of light cycles on susceptibility to audiogenic seizures and on levels of 5-hydroxytryptamine and norepinephrine in brain. Physiol Behav. 1972;8(4):699-703.

52. Cho H, Zhao X, Hatori M, et al. Regulation of circadian behaviour and metabolism by REV-ERB- $\alpha$ and REV-ERB- $\beta$. Nature. 2012;485(7396):123-127.

53. Carotenuto M, Parisi P, Esposito M, Cortese S, Elia M. Sleep alterations in children with refractory epileptic encephalopathies: a polysomnographic study. Epilepsy Behav. 2014;35:50-53.

54. Barnard AR, Nolan PM. When clocks go bad: neurobehavioural consequences of disrupted circadian timing. PLoS Genet. 2008;4(5): e1000040.

55. Quigg M, Straume M, Smith T, Menaker M, Bertram EH. Seizures induce phase shifts of rat circadian rhythms. Brain Res. 2001;913(2): $165-169$.

56. Ronkainen E, Ansakorpi H, Huikuri HV, Myllylä VV, Isojärvi JI, Korpelainen JT. Suppressed circadian heart rate dynamics in temporal lobe epilepsy. J Neurol Neurosurg Psychiatry. 2005;76(10):1382-1386.

57. Persson H, Kumlien E, Ericson M, Tomson T. Circadian variation in heart-rate variability in localization-related epilepsy. Epilepsia. 2007;48(5):917-922.

58. Fauteck J, Schmidt H, Lerchl A, Kurlemann G, Wittkowski W. Melatonin in epilepsy: first results of replacement therapy and first clinical results. Biol Signals Recept. 1999;8(1-2):105-110.

59. Schapel GJ, Beran RG, Kennaway DL, McLoughney J, Matthews CD. Melatonin response in active epilepsy. Epilepsia. 1995;36(1):75-78.

60. Stewart LS, Leung LS. Temporal lobe seizures alter the amplitude and timing of rat behavioral rhythms. Epilepsy Behav. 2003;4(2): $153-160$.

61. Stewart LS, Bercovici E, Shukla R, et al. Daily rhythms of seizure activity and behavior in a model of atypical absence epilepsy. Epilepsy Behav. 2006;9(4):564-572.

62. Quigg M, Clayburn H, Straume M, Menaker M, Bertram EH. Hypothalamic neuronal loss and altered circadian rhythm of temperature in a rat model of mesial temporal lobe epilepsy. Epilepsia. 1999;40(12):1688-1696.

63. Wither RG, Colic S, Wu C, Bardakjian BL, Zhang L, Eubanks JH. Daily rhythmic behaviors and thermoregulatory patterns are disrupted in adult female MeCP2-deficient mice. PLoS One. 2012;7(4):e35396.

64. Parekh MB, Carney PR, Sepulveda H, Norman W, King M, Mareci TH. Early MR diffusion and relaxation changes in the parahippocampal gyrus precede the onset of spontaneous seizures in an animal model of chronic limbic epilepsy. Exp Neurol. 2010;224(1):258-270.

65. Talathi SS, Hwang DU, Ditto WL, et al. Circadian control of neural excitability in an animal model of temporal lobe epilepsy. Neurosci Lett. 2009;455(2):145-149. 
66. Stanley DA, Talathi SS, Parekh MB, et al. Phase shift in the 24-hour rhythm of hippocampal EEG spiking activity in a rat model of temporal lobe epilepsy. J Neurophysiol. 2013;110(5):1070-1086.

67. Matzen J, Buchheim K, Holtkamp M. Circadian dentate gyrus excitability in a rat model of temporal lobe epilepsy. Exp Neurol. 2012;234(1):105-111.

68. Horne JA, Ostberg O. A self-assessment questionnaire to determine morningness-eveningness in human circadian rhythms. Int J Chronobiol. 1976;4(2):97-110.

69. Sack RL, Auckley D, Auger RR, et al. Circadian rhythm sleep disorders: part I, basic principles, shift work and jet lag disorders. An American Academy of Sleep Medicine review. Sleep. 2007;30(11): 1460-1483.

70. Hofstra WA, van der Palen J, de Weerd AW. Morningness and eveningness: when do patients take their antiepileptic drugs? Epilepsy Behav. 2012;23(3):320-323.

71. Pung T, Schmitz B. Circadian rhythm and personality profile in juvenile myoclonic epilepsy. Epilepsia. 2006;47 Suppl 2:111-114.

72. Hofstra WA, Gordijn MC, van Hemert-van der Poel JC, van der Palen J, De Weerd AW. Chronotypes and subjective sleep parameters in epilepsy patients: a large questionnaire study. Chronobiol Int. 2010;27(6): 1271-1286.

73. Roenneberg T, Wirz-Justice A, Merrow M. Life between clocks: daily temporal patterns of human chronotypes. J Biol Rhythms. 2003;18(1): 80-90.

74. Stern JM, Reichlin S. Prolactin circadian rhythm persists throughout lactation in women. Neuroendocrinology. 1990;51(1):31-37.

75. Szafarczyk A, Hery M, Laplante E, Ixart G, Assenmacher I, Kordon C. Temporal relationships between the circadian rhythmicity in plasma levels of pituitary hormones and in hypothalamic concentrations of releasing factors. Neuroendocrinology. 1980;30(6):369-376.

76. Lucas RJ, Stirland JA, Darrow JM, Menaker M, Loudon AS. Free running circadian rhythms of melatonin, luteinizing hormone, and cortisol in Syrian hamsters bearing the circadian tau mutation. Endocrinology. 1999;140(2):758-764.

77. Luef G. Hormonal alterations following seizures. Epilepsy Behav. 2010;19(2):131-133.

78. Herzog AG. Catamenial epilepsy: definition, prevalence pathophysiology and treatment. Seizure. 2008;17(2):151-159.

79. Herzog AG, Seibel MM, Schomer DL, Vaitukaitis JL, Geschwind N. Reproductive endocrine disorders in men with partial seizures of temporal lobe origin. Arch Neurol. 1986;43(4):347-350.

80. Herzog AG, Seibel MM, Schomer DL, Vaitukaitis JL, Geschwind N. Reproductive endocrine disorders in women with partial seizures of temporal lobe origin. Arch Neurol. 1986;43(4):341-346.

81. Herzog AG. A hypothesis to integrate partial seizures of temporal lobe origin and reproductive endocrine disorders. Epilepsy Res. 1989;3(2): 151-159.

82. Herzog AG. Altered reproductive endocrine regulation in men with epilepsy: implications for reproductive function and seizures. Ann Neurol. 2002;51(5):539-542.

83. Herzog AG, Coleman AE, Jacobs AR, et al. Interictal EEG discharges, reproductive hormones, and menstrual disorders in epilepsy. Ann Neurol. 2003;54(5):625-637.

84. Reinberg A, Halberg F. Circadian chronopharmacology. Annu Rev Pharmacol. 1971;11:455-492.

85. Zeitzer JM, Dijk DJ, Kronauer R, Brown E, Czeisler C. Sensitivity of the human circadian pacemaker to nocturnal light: melatonin phase resetting and suppression. J Physiol. 2000;526 Pt 3:695-702.

86. Johansson AS, Brask J, Owe-Larsson B, Hetta J, Lundkvist GB. Valproic acid phase shifts the rhythmic expression of Period2::Luciferase. J Biol Rhythms. 2011;26(6):541-551.

87. Loddenkemper T. Chrono-epileptology: time to reconsider seizure timing. Seizure. 2012;21(6):411

88. Youan BB. Chronopharmaceutics: gimmick or clinically relevant approach to drug delivery? J Control Release. 2004;98(3):337-353.
89. Ramgopal S, Thome-Souza S, Loddenkemper T. Chronopharmacology of anti-convulsive therapy. Curr Neurol Neurosci Rep. 2013; 13(4):339.

90. Dallmann R, Brown SA, Gachon F. Chronopharmacology: new insights and therapeutic implications. Annu Rev Pharmacol Toxicol. 2014;54:339-361.

91. Nelson W, Tong YL, Lee JK, Halberg F. Methods for cosinor-rhythmometry. Chronobiologia. 1979;6(4):305-323.

92. Smolensky MH, Lemmer B, Reinberg AE. Chronobiology and chronotherapy of allergic rhinitis and bronchial asthma. Adv Drug Deliv Rev. 2007;59(9-10):852-882.

93. Nicholson PA, Bogie W. Diurnal variation in the symptoms of hay fever: implications for pharmaceutical development. Curr Med Res Opin. 1973;1(7):395-400.

94. Reinberg A, Gervais P, Ugolini C, Del Cerrro L, Bicakova-Rocher A. A multicentric chronotherapeutic study of mequitazine in allergic rhinitis. Annu Rev Chronopharmacol. 1985;3:441-444.

95. Reinberg A. Chronopharmacology of H1-antihistamines. In: Lemmer BJ, editor. Chronopharmacology: Cellular and Biochemical Interactions. New York, NY, USA: Marcel Dekker; 1989.

96. Reinberg A, Levi F, Guillet P, Burke JT, Nicolai A. Chronopharmacological study of antihistamines in man with special references to terfenadine. Eur J Clin Pharmacol. 1978;14(4):245-252.

97. Reinberg A, Sidi E. Circadian changes in the inhibitory effects of an antihistaminic drug in man. J Invest Dermatol. 1966;46(4):415-419.

98. Reinberg A, Levi F, Fourtillan J, Pfeiffer C, Bichakova-Rocher A, Nocolai A. Antihistamine and other effects of $5 \mathrm{mg}$ mequitazine vary between morning and evening acute administration. Annu Rev Chronopharmacol. 1984;1:57-60.

99. Tekade AR, Gattani SG. Dual cross-linked pulsatile beads for chronotherapy of asthma: development and evaluation. Drug Deliv. 2010;17(8):581-586.

100. Storms WW, Nathan RA, Bodman SF, et al. The effect of repeat action albuterol sulfate (Proventil Repetabs) in nocturnal symptoms of asthma. J Asthma. 1992;29(3):209-216.

101. Ranjan OP, Nayak UY, Reddy MS, Dengale SJ, Musmade PB, Udupa N. Osmotically controlled pulsatile release capsule of montelukast sodium for chronotherapy: statistical optimization, in vitro and in vivo evaluation. Drug Deliv. November 12, 2013. [Epub ahead of print.]

102. Jain D, Raturi R, Jain V, Bansal P, Singh R. Recent technologies in pulsatile drug delivery systems. Biomatter. 2011;1(1):57-65.

103. Tran TH, Lee BJ. On-off pulsed oral drug-delivery systems: a possible tool for drug delivery in chronotherapy. Ther Deliv. 2011;2(9):1199-1214.

104. Lévi F, Okyar A. Circadian clocks and drug delivery systems: impact and opportunities in chronotherapeutics. Expert Opin Drug Deliv. 2011;8(12):1535-1541

105. Coogan AN, Schutová B, Husung S, et al. The circadian system in Alzheimer's disease: disturbances, mechanisms, and opportunities. Biol Psychiatry. 2013;74(5):333-339.

106. Bruguerolle B, Simon N. Biologic rhythms and Parkinson's disease: a chronopharmacologic approach to considering fluctuations in function. Clin Neuropharmacol. 2002;25(4):194-201.

107. Miller A, Avidan N, Tzunz-Henig N, et al. Translation towards personalized medicine in multiple sclerosis. J Neurol Sci. 2008;274(1-2): 68-75.

108. Glass-Marmor L, Paperna T, Ben-Yosef Y, Miller A. Chronotherapy using corticosteroids for multiple sclerosis relapses. J Neurol Neurosurg Psychiatry. 2007;78(8):886-888.

109. Morton AJ, Wood NI, Hastings MH, Hurelbrink C, Barker RA, Maywood ES. Disintegration of the sleep-wake cycle and circadian timing in Huntington's disease. J Neurosci. 2005;25(1):157-163.

110. Morton AJ. Circadian and sleep disorder in Huntington's disease. Exp Neurol. 2013;243:34-44.

111. Dowling GA, Burr RL, Van Someren EJ, et al. Melatonin and brightlight treatment for rest-activity disruption in institutionalized patients with Alzheimer's disease. J Am Geriatr Soc. 2008;56(2):239-246. 
112. Meinardi H, Van Der Kleijn E, Meijer JW, Van Rees H. Absorption and distribution of antiepileptic drugs. Epilepsia. 1975;16(2):353-365.

113. Yoshiyama Y, Nakano S, Ogawa N. Chronopharmacokinetic study of valproic acid in man: comparison of oral and rectal administration. J Clin Pharmacol. 1989;29(11):1048-1052.

114. Ohdo S, Nakano S, Ogawa N. Chronopharmacokinetics of valproic acid following constant-rate administration in mice. Chronobiol Int. 1991;8(1):35-43.

115. Klotz U, Reimann IW. Chronopharmacokinetic study with prolonged infusion of midazolam. Clin Pharmacokinet. 1984;9(5):469-474.

116. Nakano $S$, Watanabe $H$, Nagai $K$, Ogawa $N$. Circadian stage-dependent changes in diazepam kinetics. Clin Pharmacol Ther. 1984;36(2): 271-277.

117. Perucca E. An introduction to antiepileptic drugs. Epilepsia. 2005; 46(Suppl 4):31-37.

118. Patsalos PN, Berry DJ, Bourgeois BF, et al. Antiepileptic drugs - best practice guidelines for therapeutic drug monitoring: a position paper by the subcommission on therapeutic drug monitoring, ILAE Commission on Therapeutic Strategies. Epilepsia. 2008;49(7):1239-1276.

119. Ben-CherifW, Dridi I, Aouam K, Ben-Attia M, Reinberg A, Boughattas NA. Chronotolerance study of the antiepileptic drug valproic acid in mice. J Circadian Rhythms. 2012;10:3.

120. Oggier DM, Weisbrod CJ, Stoller AM, Zenker AK, Fent K. Effects of diazepam on gene expression and link to physiological effects in different life stages in zebrafish Danio rerio. Environ Sci Technol. 2010;44(19):7685-7691.

121. Djeridane Y, Touitou Y. Chronic diazepam administration differentially affects melatonin synthesis in rat pineal and Harderian glands. Psychopharmacology (Berl). 2001;154(4):403-407.

122. Carpentieri AR, Pujolràs MA, Chiesa JJ, Noguera AD, Cambras T. Effect of melatonin and diazepam on the dissociated circadian rhythm in rats. J Pineal Res. 2006;40(4):318-325.

123. Dokucu ME, Yu L, Taghert PH. Lithium- and valproate-induced alterations in circadian locomotor behavior in Drosophila. Neuropsychopharmacology. 2005;30(12):2216-2224.

124. Placidi F, Diomedi M, Scalise A, Marciani MG, Romigi A, Gigli GL. Effect of anticonvulsants on nocturnal sleep in epilepsy. Neurology. 2000;54(5 Suppl 1):S25-S32.

125. Jain SV, Glauser TA. Effects of epilepsy treatments on sleep architecture and daytime sleepiness: an evidence-based review of objective sleep metrics. Epilepsia. 2014;55(1):26-37.

126. Guilhoto LM, Loddenkemper T, Vendrame M, Bergin A, Bourgeois BF, Kothare SV. Higher evening antiepileptic drug dose for nocturnal and early-morning seizures. Epilepsy Behav. 2011;20(2):334-337.

127. Yegnanarayan R, Mahesh SD, Sangle S. Chronotherapeutic dose schedule of phenytoin and carbamazepine in epileptic patients. Chronobiol Int. 2006;23(5):1035-1046.

128. Baxendale SA. Light therapy as a treatment for epilepsy. Med Hypotheses. 2011;76(5):661-664.

129. Baxendale S, O’Sullivan J, Heaney D. Bright light therapy as an add on treatment for medically intractable epilepsy. Epilepsy Behav. 2012;24(3):359-364.

130. Molina-Carballo A, Munoz-Hoyos A, Sanchez-Forte M, Uberos-Fernandez J, Moreno-Madrid F, Acuna-Castroviejo D. Melatonin increases following convulsive seizures may be related to its anticonvulsant properties at physiological concentrations. Neuropediatrics. 2007;38(3):122-125.

131. Sanchez-Barcelo EJ, Mediavilla MD, Reiter RJ. Clinical uses of melatonin in pediatrics. Int J Pediatr. 2011;2011:892624.

132. Brigo F, Del Felice A. Melatonin as an add on treatment for epilepsy. Cochrane Database Syst Rev. 2012;6:CD006967.

133. Morrell MJ; RNS System in Epilepsy Study Group. Responsive cortical stimulation for the treatment of medically intractable partial epilepsy. Neurology. 2011;77(13):1295-1304.

134. Sun FT, Morrell MJ, Wharen RE Jr. Responsive cortical stimulation for the treatment of epilepsy. Neurotherapeutics. 2008;5(1): $68-74$.
135. Poh MZ, Loddenkemper T, Reinsberger C, et al. Convulsive seizure detection using a wristworn electrodermal activity and accelerometry biosensor. Epilepsia. 2012;53(5):93-97.

136. Misra A, Ganesh S, Shahiwala A, Shah SP. Drug delivery to the central nervous system: a review. J Pharm Pharm Sci. 2003;6(2):252-273.

137. Cho K. Chronic 'jet lag' produces temporal lobe atrophy and spatial cognitive deficits. Nat Neurosci. 2001;4(6):567-568.

138. Cho K, Ennaceur A, Cole JC, Suh CK. Chronic jet lag produces cognitive deficits. J Neurosci. 2000;20(6):RC66.

139. Bertilsson L. Clinical pharmacokinetics of carbamazepine. Clin Pharmacokinet. 1978;3(2):128-143.

140. National Highway Safety Authority. Drug Information and Performance Fact Sheet. Available from: http://www.nhtsa.gov/people/ injury/research/job185drugs/diazepam.htm. Accessed July 22, 2014.

141. Kaplan SA, Jack ML, Alexander K, Weinfeld RE. Pharmacokinetic profile of diazepam in man following single intravenous and oral and chronic oral administrations. J Pharm Sci. 1973;62(11): 1789-1796.

142. Cloyd JC, Lalonde RL, Beniak TE, Novack GD. A single-blind, crossover comparison of the pharmacokinetics and cognitive effects of a new diazepam rectal gel with intravenous diazepam. Epilepsia. 1998;39(5):520-526.

143. Riss J, Cloyd J, Gates J, Collins S. Benzodiazepines in epilepsy: pharmacology and pharmacokinetics. Acta Neurol Scand. 2008;118(2): 69-86.

144. Medscape. Diazepam. Available from: http://reference.medscape.com/ drug/valium-diastat-diazepam-342902-10. Accessed July 22, 2014.

145. Hvidberg EF, Dam M. Clinical pharmacokinetics of anticonvulsants. Clin Pharmacokinet. 1976;1(3):161-188.

146. Doty P, Rudd GD, Stoehr T, Thomas D. Lacosamide. Neurotherapeutics. 2007;4(1):145-148.

147. Italiano D, Perucca E. Clinical pharmacokinetics of new-generation antiepileptic drugs at the extremes of age: an update. Clin Pharmacokinet. 2013;52(8):627-645.

148. Rambeck B, Wolf P. Lamotrigine clinical pharmacokinetics. Clin Pharmacokinet. 1993;25(6):433-443.

149. Ramsay RE, Pellock JM, Garnett WR, et al. Pharmacokinetics and safety of lamotrigine (Lamictal) in patients with epilepsy. Epilepsy Res. 1991;10(2-3):191-200.

150. Perucca E, Gidal BE, Baltès E. Effects of antiepileptic comedication on levetiracetam pharmacokinetics: a pooled analysis of data from randomized adjunctive therapy trials. Epilepsy Res. 2003;53(1-2):47-56.

151. Greenblatt DJ, Shader RI, Franke K, et al. Pharmacokinetics and bioavailability of intravenous, intramuscular, and oral lorazepam in humans. J Pharm Sci. 1979;68(1):57-63.

152. Greenblatt DJ, Divoll M, Harmatz JS, Shader RI. Pharmacokinetic comparison of sublingual lorazepam with intravenous, intramuscular, and oral lorazepam. J Pharm Sci. 1982;71(2):248-252.

153. Medscape. Midazolam. Available from: http://reference.medscape. com/drug/versed-midazolam-342907-10. Accessed July 22, 2014.

154. May TW, Korn-Merker E, Rambeck B. Clinical pharmacokinetics of oxcarbazepine. Clin Pharmacokinet. 2003;42(12):1023-1042.

155. Berg MJ, Berlinger WG, Goldberg MJ, Spector R, Johnson GF. Acceleration of the body clearance of phenobarbital by oral activated charcoal. N Engl J Med. 1982;307(11):642-644.

156. Brandolese R, Scordo MG, Spina E, Gusella M, Padrini R. Severe phenytoin intoxication in a subject homozygous for CYP2C $9 * 3$. Clin Pharmacol Ther. 2001;70(4):391-394.

157. Pfizer. Dilantin. Available from: http://labeling.pfizer.com/ ShowLabeling.aspx?id=545. Accessed July 22, 2014.

158. Rosenfeld WE, Doose DR, Walker SA, Baldassarre JS, Reife RA. A study of topiramate pharmacokinetics and tolerability in children with epilepsy. Pediatr Neurol. 1999;20(5):339-344.

159. Medscape. Valproic acid. Available from: http://reference.medscape. com/drug/depakene-stavzor-valproic-acid-343024-10. Accessed July 22, 2014. 
ChronoPhysiology and Therapy

\section{Publish your work in this journal}

ChronoPhysiology and Therapy is an international, peer-reviewed, open access journal focusing on research into the cyclic variations and rhythmicity in physiological processes in the body and the research and development and optimal timing of administration of therapeutic targets to achieve improved outcomes and quality of life for the patient. The

vanagement system is completely online and includes a very quick and fair peer-review system. Visit http://www.dovepress.com/ testimonials.php to read real quotes from published authors.

Submit your manuscript here: http://www.dovepress.com/chronophysiology-and-therapy-journal 